Article

\title{
Fabrication of a High-Performance Bending Actuator Made with a PVC Gel
}

\author{
Eun-Jae Shin, Won-Hyeong Park and Sang-Youn Kim * iD \\ Interaction Laboratory, Advanced Research Technology Center, Korea University of Technology and Education, \\ Chungjeol-ro, Byeongcheon-myeon, Dongnam-gu, Cheonan, ChungNam 330-708, Korea; \\ ejshin@koreatech.ac.kr (E.-J.S.); ipo1001@koreatech.ac.kr (W.-H.P.) \\ * Correspondence: sykim@koreatech.ac.kr; Tel.: +82-41-560-1461
}

Received: 3 June 2018; Accepted: 28 July 2018; Published: 1 August 2018

\begin{abstract}
This paper proposes a small, transparent, electroactive and highly deformable poly vinyl chloride (PVC) gel-based bending actuator. The effect of the PVC molecular weight and plasticizer content on the performance of the bending actuator is investigated. Three PVCs are prepared with different molecular weights (low molecular weight: $\mathrm{PVC}_{\mathrm{L}}, 116,000$; medium molecular weight: $\mathrm{PVC}_{\mathrm{M}}$, 239,000; and high molecular weight: $\left.\mathrm{PVC}_{\mathrm{H}}, 282,000\right)$ and mixed with plasticizers in various ratios to achieve the best performance of the bending actuator. Experiments are conducted to investigate the bending performance of the actuators based on the prepared PVC gels. Among the prepared actuators, the $\mathrm{PVC}_{\mathrm{H}}$-based bending actuator shows the best performance (maximum bending angle: $180^{\circ}$, elapsed time: $\left.3.15 \mathrm{~s}\right)$.
\end{abstract}

Keywords: electroactive gel; creep deformation; transparent electroactive polymer

\section{Introduction}

Recently, tiny but highly deformable bending actuators based on smart materials are being actively studied because they have many advantages such as being lightweight, small and simple operating mechanisms [1-5]. Among various smart material-based bending actuators, electroactive polymers (EAPs), which are operated by electric energy, are widely used. These electroactive polymers can be classified into two types: ionic and nonionic polymers. An ionic polymer/metal composite (IPMC) is one of the most popular ionic polymers for bending actuators. It consists of an ion-exchangeable membrane (ex, Nafion film) and electrodes. The IPMC-based bending actuators were widely studied over the past few decades, and they are still improving nowadays [6-8]. Indrek Must et al. presented a bending actuator using an IPMC with carbon for worm-like robots [7]. Ajahar Khan et al. proposed a new ion-exchangeable membrane (polyaniline thorium phosphate (ThP-PANI) composite) to substitute a Nafion film, which has drawbacks such as high cost, low water-retention capability and back-relaxation, and developed a bending actuator based on the IPMC with the new ionic-exchangeable membrane [8]. Poly vinyl alcohols (PVAs) are another candidate material for fabricating bending actuators. Fan Wang et al. introduced a PVA-2,2,6,6-tetramethylpy-peridine-1-oxyl-oxidized bacterial cellulose nanofiber (TOCN)-based bending actuator [9]. Xuan-Lun Wang et al. enhanced the actuation performance of a bending actuator based on PVA by improving proton conductivity and ionic-exchangeable capacity [10]. Jiahua Shi et al. tried to mix multi-wall carbon nanotubes (MWCNTs) with PVA to enhance the electromechanical property of PVA in order to develop a bending actuator [11]. Gang Zhao et al. fabricated another type of an ionic polymer using a biopolymer (chitosan polymer) and ionic liquid, and then developed a bending actuator based on the ionic polymer [12]. Liang Gao et al. proposed a bending actuator using a post-synthetic modification of PVA and $N^{1}, N^{1}$-diethylethane-1,2-diamine (DEEDA) (PVA-DEEDA) [13]. Jian-Ke Sun et al. developed 
a metal-organic framework hybrid nanoporous membrane-based bending actuator [14]. Although there are many advantages (such as light weight and low power consumption) in ionic polymers and there have been lots of attempts to enhance the performance of bending actuators based on ionic polymers, the polyelectrolyte is vulnerable to solvent evaporation, and application of the electric field is inevitably accompanied by an electrolysis reaction.

On the other hand, nonionic EAP-based bending actuators, which are composed of dielectric polymers covered with stretchable electrodes on both sides, have a fast response time. Jun Shintake et al. developed a bending actuator using a dielectric polymer for a soft gripper [15]. Guggi Kofod et al. designed a bending actuator having a minimum-energy structure based on a dielectric polymer [16]. When voltage is applied to the electrode, a dielectric material quickly expands in planar directions and compresses in the thickness direction. Because the nonionic EAPs do not need electrolyte, they are operated in air conditions. However, the nonionic EAPs require a prestretching process to maximize their deformation and they need stretchable electrodes for their operation. Among many nonionic EAPs, polyvinylidene fluoride (PVDF) is one of the most attractive and representative nonionic polymers for fabricating bending actuators. I. Chilibon et al. introduced a bending actuator using prepolarized piezoelectric bimorph structure consisting of two PVDF thin films [17]. R. Mejri et al. proposed a new method to fabricate a high-performance bending actuator using an ionic liquid/PVDF blend [18]. Babita Gaihre et al. synthesized a PPy-PVDF multilayered electroactive polymer and fabricated a bending actuator using the PPy-PVDF multilayered polymer [19]. Tian Chen and Bo Liu enhanced the performance of the bending transducer by applying graphene quantum dots to PVDF [20]. The PVDF-based bending actuators are widely used and researched, and furthermore they are enhanced via various methods nowadays. However, they need highly stretchable electrodes for achieving a large bending behavior.

T. Hirai et al. [21,22] has presented a poly vinyl chloride (PVC) gel, which could solve the above problems, as an electroactive material for bending actuators. PVC gel-based bending actuators work well in air and do not require stretchable electrodes. Another great advantage of PVC gel-based bending actuators is that they are transparent. Even though a bending actuator based on an electroactive PVC gel does not need stretchable electrodes, there are still problems to be solved in that its response time is slow and its bending angle is not large. We inserted 12 related works in the reference section.

Previously, we synthesized PVC and dibutyl adipate (DBA) to fabricate an electroactive PVC gel $[23,24]$. When a voltage was applied to the developed electroactive PVC gel, the plasticizers in the PVC matrix migrated to the anode side with dragging PVC chains, consequently deforming the PVC gel. As soon as the voltage was removed, the PVC gel returned to its original shape due to its elasticity. Thus, we can readily assume that the stiffness of a PVC gel affects the performance of the PVC gel-based bending actuator. If the stiffness of the PVC gel is too great, its deformation becomes small. In contrast, a compliant PVC gel is deformed a great deal by a small voltage. A large amount of plasticizer not only makes the electroactive gel softer, but also increases the number of moving dipoles so that large amounts of plasticizers deform the PVC gel more. In other words, the actuation performance of the PVC gel is strongly related to the amount of plasticizer added.

The crystallinity, entanglement and physical crosslinking in PVC resins are affected by their molecular weight $[25,26]$. Thus, using PVC resins of different molecular weights would change the mechanical properties of PVC gels. PVC is a semicrystalline polymer having a 3-D crosslinking network. As the molecular weight of PVC increases, the crystalline region inside the PVC also increases. For this reason, the higher the molecular weight of the PVC resin used, the greater the area within the PVC that can be plasticized. Furthermore, a PVC with high molecular weight has denser entanglement and more physical crosslinking, so excess plasticizer can be retained in the PVC chain matrix. Previously, we investigated the effect of the molecular weight of the PVC resin on the electroactive performance of plasticized PVC gels [27]. Because a high-molecular-weight PVC can accept more plasticizer, the performance of PVC gels based on high-molecular-weight PVC resin increases. In this paper, we investigated the electrical and mechanical properties of a PVC 
gel-based actuator in relation to its molecular weight and plasticizer content. Then, we fabricated a high-performance PVC gel-based actuator. The dynamic mechanical property of the proposed actuator was also investigated, and bending performance examined in terms of response time and maximum bending angle.

\section{Experiment}

An electroactive PVC gel was fabricated using poly vinyl chloride (PVC), tetrahydrofuran (THF) as a solvent, and dibutyl adipate (DBA) as the plasticizer. The process for fabrication of the electroactive PVC gel is shown in Figure 1. First, we poured PVC powder and DBA (Sigma-Aldrich, St. Louis, MO, USA) plasticizer into the THF (Sigma-Aldrich, St. Louis, MO, USA) solvent, and then stirred the solution (we call it PVC-DBA solution) for $4 \mathrm{~h}$ to fully dissolve the PVC and the DBA in the THF solvent. To obtain flat, transparent PVC gel, we poured the fully dissolved PVC-DBA solution into a Teflon dish; then we dried the solution for $72 \mathrm{~h}$ at room temperature. To evaporate the THF fully in the solution, we put the solution into a vacuum oven for $24 \mathrm{~h}$. Finally, we obtained a transparent, electroactive, physically crosslinked and flat PVC gel, 1 mm thick.

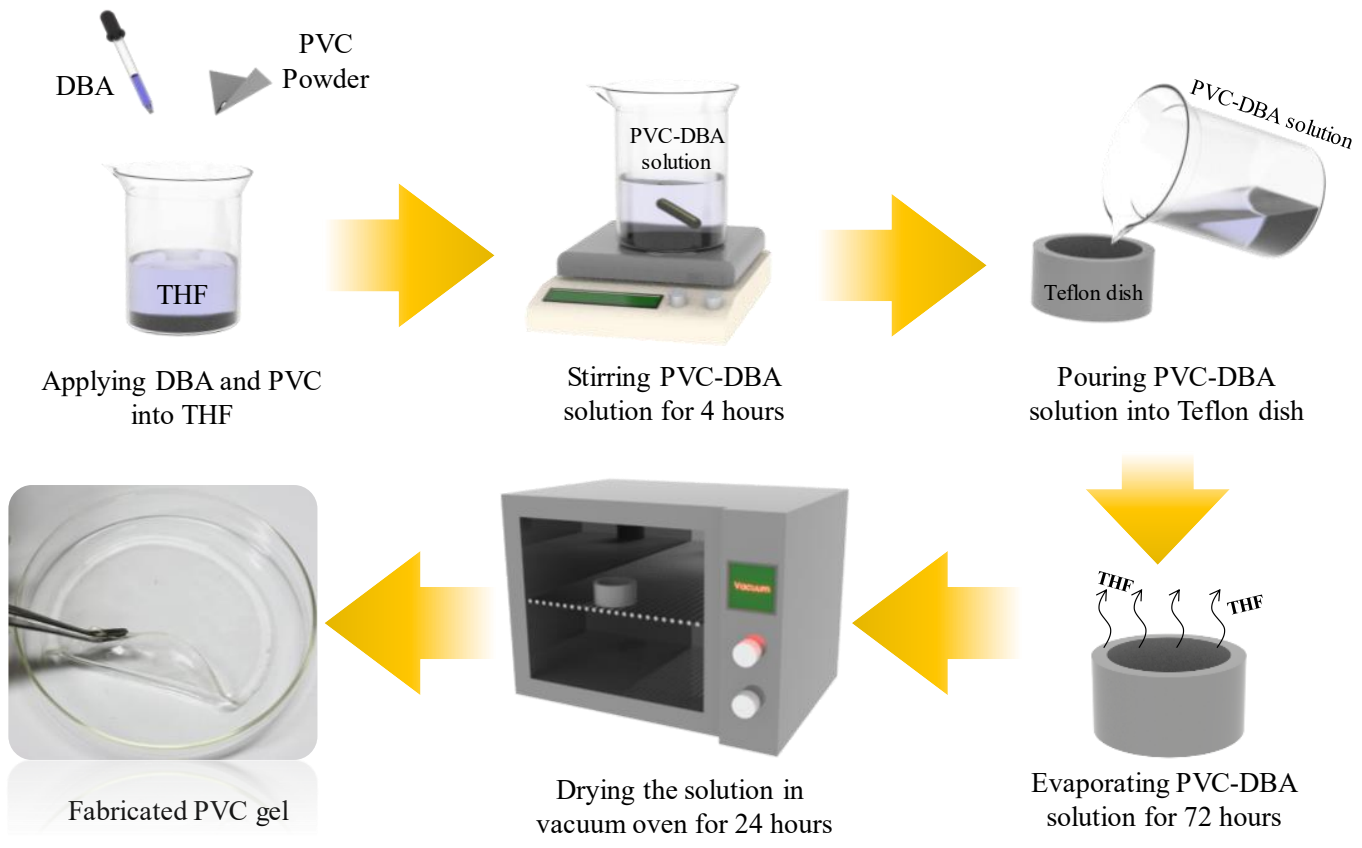

Figure 1. Process for fabrication of the electroactive PVC (poly vinyl chloride) gel.

Two electrodes were attached, one on each side of the PVC gel, to fabricate a transparent bending actuator, as shown in Figure 2a, where the PVC gel, PVC chains and dipoles in the PVC gel are colored aquamarine, white and red, respectively. Figure $2 b$ shows the fabricated bending actuator, and Figure 2c,d show the voltage-off and -on states (respectively) of the proposed actuator. When we applied voltage input to the proposed actuator, the dipoles (DBA plasticizer) rotated and reoriented, then moved toward the anode, dragging the PVC chains. Thus, the PVC gel was deformed toward the anode, as shown in Figure 2d. In the voltage-off state, electric field-induced deformation does not occur because the dipoles are randomly distributed in the PVC gel. 


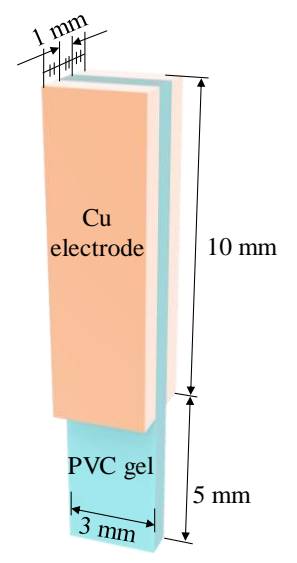

(a)

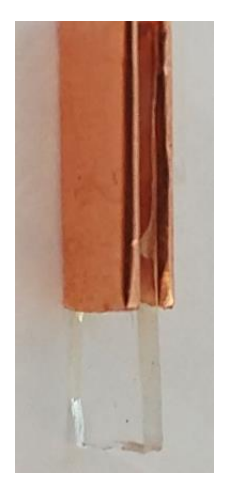

(b)

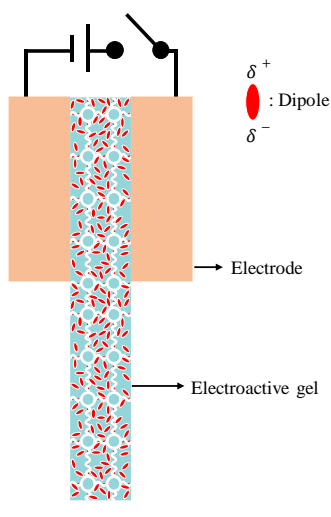

(c)

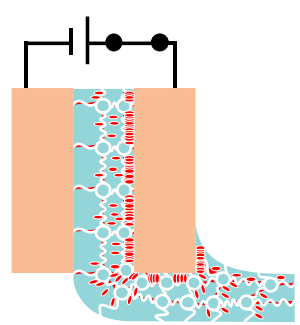

(d)

Figure 2. Structure and operating principle of the PVC gel-based bending actuator: (a) Structure of the proposed bending actuator, (b) fabricated bending actuator, (c) voltage-off state, and (d) voltage-on state.

As we mentioned before, the performance of the PVC gel-based bending actuator is closely related not only to the plasticizer content but also to the molecular weight of the PVC. When the PVC gel is fabricated using a high-molecular-weight PVC resin, it can contain more plasticizer than a low-molecular-weight PVC-based gel. Furthermore, because a high-molecular-weight PVC gel has more entanglement and more physical crosslinking than a lower-molecular-weight PVC gel, the density of the PVC chains in the high-molecular-weight PVC gel is higher than in a PVC gel based on low-molecular-weight PVC. Under voltage input, the PVC chains and the plasticizer move toward the anode. At that time, the plasticizers in the high-molecular-weight PVC gel can accelerate the movement of PVC chains toward an anode. Because there are many more PVC chains near an anode in the high-molecular-weight PVC gel than in the lower-molecular-weight PVC gel, more PVC chains can be influenced by applied electric field [27]. For these reasons, we expect that the molecular weight of the PVC will affect the deformation of the PVC gel-based bending actuator and its response time.

To investigate the molecular weight effect of the PVC gel-based bending actuator, we prepared three commercial PVCs ( $\mathrm{PVC}_{\mathrm{L}}$ : Wako; $\mathrm{PVC}_{\mathrm{M}}$ : Sigma-Aldrich; and $\mathrm{PVC}_{\mathrm{H}}$ : Scientific Polymer), with molecular weights of 116,000, 239,000 and 282,000, respectively. Furthermore, to observe the plasticizer effect, we fabricated PVC gels with different weight ratios of PVC resin to DBA plasticizer: 1:0, 1:3, 1:5, 1:7, 1:9, 1:11 and 1:13 denoted as PVC0 (PVC film), PVC3, PVC5, PVC7, PVC9, PVC11 and $\mathrm{PVC} 13$, respectively. In this preparation, for $\mathrm{PVC}_{\mathrm{L}}$, we could only obtain $\mathrm{PVC}_{\mathrm{L}} 3$ and $\mathrm{PVC}_{\mathrm{L}} 5$ because the $P_{V V} C_{L}$ has low entanglement, low physical crosslinking, and a small crystalline region. If the ratio of $\mathrm{PVC}_{\mathrm{L}}$ to plasticizer was more than 1:5, we could not obtain a PVC gel. Hence, we prepared $17 \mathrm{PVC}$ gels as shown in Table $1\left(\mathrm{PVC}_{\mathrm{L}} 0, \mathrm{PVC}_{\mathrm{L}} 3, \mathrm{PVC}_{\mathrm{L}} 5, \mathrm{PVC}_{\mathrm{M}} 0, \mathrm{PVC}_{\mathrm{M}} 3, \mathrm{PVC}_{\mathrm{M}} 5, \mathrm{PVC}_{\mathrm{M}} 7, \mathrm{PVC}_{\mathrm{M}} 9, \mathrm{PVC}_{\mathrm{M}} 11\right.$, $\mathrm{PVC}_{\mathrm{M}} 13, \mathrm{PVC}_{\mathrm{H}} 0, \mathrm{PVC}_{\mathrm{H}} 3, \mathrm{PVC}_{\mathrm{H}} 5, \mathrm{PVC}_{\mathrm{H}} 7, \mathrm{PVC}_{\mathrm{H}} 9, \mathrm{PVC}_{\mathrm{H}} 11$ and $\left.\mathrm{PVC}_{\mathrm{H}} 13\right)$.

Table 1. Prepared PVC gels with DBA (dibutyl adipate) plasticizer and PVC of various molecular weights.

\begin{tabular}{|c|c|c|c|c|c|c|c|c|}
\hline \multirow{2}{*}{$\begin{array}{c}\begin{array}{c}\text { Base } \\
\text { Material }\end{array} \\
\mathrm{PVC}_{\mathrm{L}} \\
\end{array}$} & \multirow{2}{*}{$\begin{array}{c}\begin{array}{c}\text { Molecular } \\
\text { Weight (Mw) }\end{array} \\
116,000\end{array}$} & \multicolumn{7}{|c|}{ Weight Ratio of PVC to DBA } \\
\hline & & $\begin{array}{c}1: 0 \\
\left(\mathrm{PVC}_{\mathrm{L}} 0\right)\end{array}$ & $\begin{array}{c}1: 3 \\
\left(\mathrm{PVC}_{\mathrm{L}} 3\right)\end{array}$ & $\begin{array}{c}1: 5 \\
\left(\mathrm{PVC}_{\mathrm{L}} 5\right)\end{array}$ & & Hard to $b$ & fabricated & \\
\hline $\mathrm{PVC}_{\mathrm{M}}$ & 239,000 & $\begin{array}{c}1: 0 \\
\left(\mathrm{PVC}_{\mathrm{M}} 0\right)\end{array}$ & $\begin{array}{c}1: 3 \\
\left(\mathrm{PVC}_{\mathrm{M}} 3\right)\end{array}$ & $\begin{array}{c}1: 5 \\
\left(\mathrm{PVC}_{\mathrm{M}} 5\right)\end{array}$ & $\begin{array}{c}1: 7 \\
\left(\mathrm{PVC}_{\mathrm{M}} 7\right)\end{array}$ & $\begin{array}{c}1: 9 \\
\left(\mathrm{PVC}_{\mathrm{M}} 9\right)\end{array}$ & $\begin{array}{c}1: 11 \\
\left(\mathrm{PVC}_{\mathrm{M}} 11\right)\end{array}$ & $\begin{array}{c}1: 13 \\
\left(\mathrm{PVC}_{\mathrm{M}} 13\right)\end{array}$ \\
\hline $\mathrm{PVC}_{\mathrm{H}}$ & 282,000 & $\begin{array}{c}1: 0 \\
\left(\mathrm{PVC}_{\mathrm{H}} 0\right)\end{array}$ & $\begin{array}{c}1: 3 \\
\left(\mathrm{PVC}_{\mathrm{H}} 3\right)\end{array}$ & $\begin{array}{c}1: 5 \\
\left(\mathrm{PVC}_{\mathrm{H}} 5\right)\end{array}$ & $\begin{array}{c}1: 7 \\
\left(\mathrm{PVC}_{\mathrm{H}} 7\right)\end{array}$ & $\begin{array}{c}1: 9 \\
\left(\mathrm{PVC}_{\mathrm{H}} 9\right)\end{array}$ & $\begin{array}{c}1: 11 \\
\left(\mathrm{PVC}_{\mathrm{H}} 11\right)\end{array}$ & $\begin{array}{c}1: 13 \\
\left(\mathrm{PVC}_{\mathrm{H}} 13\right)\end{array}$ \\
\hline
\end{tabular}




\section{Results and Discussion}

Because the crystalline region of PVC is a turbid state, increase of the PVC molecular weight decreases the optical transmittance [23,24]. To show this effect, we prepared three PVC films (1 mm thick) with different molecular weights and measured their transmittance on indium tin oxide (ITO) glass using UV-vis spectroscopy (HP 8452, HP, Palo Alto, CA, USA). Figure 3a shows the transmittance of the prepared pure PVC films. The optical transmittances of the $\mathrm{PVC}_{\mathrm{L}}, \mathrm{PVC}_{\mathrm{M}}$ and $\mathrm{PVC}_{\mathrm{H}}$ films at $550 \mathrm{~nm}$ were measured and found to be $48.9 \%, 46.1 \%$ and $37.6 \%$, respectively. This result shows that the optical transmittance of pure PVC films decreases as we increase the PVC's molecular weight.

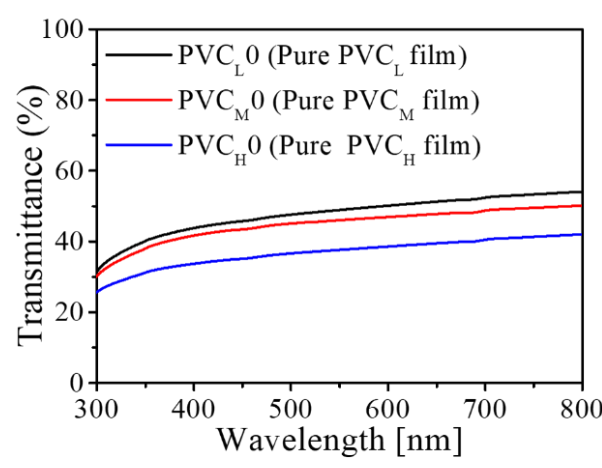

(a)

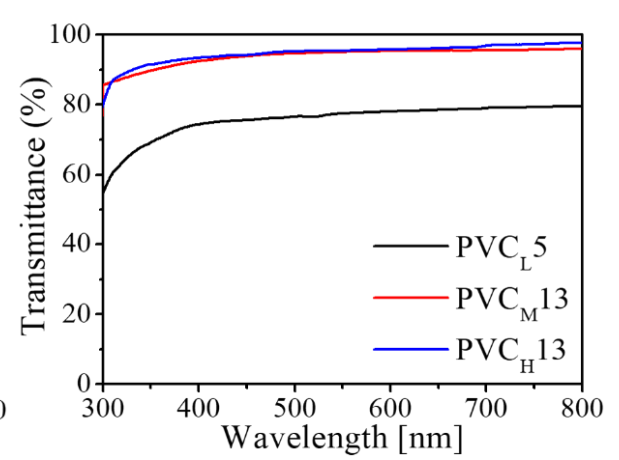

(b)

Figure 3. Optical property of the PVC films and gels: (a) Transmittance of the PVC films and (b) transmittance of the PVC gels.

The transmittance of the PVC gels was also measured. The measurement system and the procedure were the same as for the pure PVC films. As we mentioned before, we prepared $17 \mathrm{PVC}$ gels. The prepared $17 \mathrm{PVC}$ gels were divided into three groups $\left(\mathrm{PVC}_{\mathrm{L}}\right.$-based gel, $\mathrm{PVC}_{\mathrm{M}}$-based gel and $\mathrm{PVC}_{\mathrm{H}}$-based gel). We selected the PVC gel with the greatest amount of plasticizer for each PVC gel group. The selected PVC gels were $\mathrm{PVC}_{\mathrm{L}} 5, \mathrm{PVC}_{\mathrm{M}} 13$ and $\mathrm{PVC}_{\mathrm{H}} 13$. Normally, the plasticizers extend the gap between PVC chains and increase the free volume of the PVC gel. Due to these effects, the crystalline region of a PVC polymer is changed into an amorphous region with entanglement and physical crosslinking. Therefore, the transmittance of the PVC gel becomes higher than that of pure PVC films. Furthermore, comparing two PVC gels $\left(\mathrm{PVC}_{\mathrm{M}} 13\right.$ and $\left.\mathrm{PVC}_{\mathrm{H}} 13\right)$ with the same plasticizer content but different molecular weights, the transparency of $\mathrm{PVC}_{\mathrm{M}} 13(95.1 \%)$ was almost the same as that of $\mathrm{PVC}_{\mathrm{H}} 13(95.4 \%)$ at $550 \mathrm{~nm}$. This result implies that most of the crystalline regions in the PVC resin changed into amorphous regions during gel formation.

Strain-stress relationships of three pure PVC films $\left(\mathrm{PVC}_{\mathrm{L}} 0, \mathrm{PVC}_{\mathrm{M}} 0\right.$ and $\left.\mathrm{PVC}_{\mathrm{H}} 0\right)$ were measured using a Universal Tensile Machine (UTM, Tinius Olsen, H5KT) to confirm that PVCs with different molecular weights had different mechanical properties. For the experiment, dumbbell-shaped PVC films according to ASTM D638 type-V were prepared. The crosshead speed of the UTM was determined to be $50 \mathrm{~mm} / \mathrm{min}$. In Figure 4, we can observe the mechanical properties (including the toughness and the break point) of the three prepared pure PVC films. This result indicates that the crystalline region of the PVC film increases with increasing molecular weight (same as the result for the transmittance). In addition, the strain and the break point of the PVC film increase as the molecular weight of the PVC increases. Because the entanglement and physical crosslinking in the amorphous region of the PVC increase with increasing molecular weight of the PVC, the PVC can stand more applied stress. Taken together, the increase of the PVC molecular weight causes a larger crystalline region, with more entanglement and physical crosslinking, in the PVC.

The mechanical property of the PVC gel is one of the most important factors affecting the actuation performance of the PVC gel-based bending actuator. Therefore, an experiment to investigate the mechanical properties of PVC gels was conducted using the same UTM as the one we used in the 
previous experiments. We prepared 14 PVC gel samples: two PVC gels with low molecular weight $\left(\mathrm{PVC}_{\mathrm{L}} 3\right.$ and $\left.\mathrm{PVC}_{\mathrm{L}} 5\right)$, six $\mathrm{PVC}$ gels with medium molecular weight $\left(\mathrm{PVC}_{\mathrm{M}}\right)$, and six $\mathrm{PVC}$ gels with high molecular weight $\left(\mathrm{PVC}_{\mathrm{H}}\right)$.

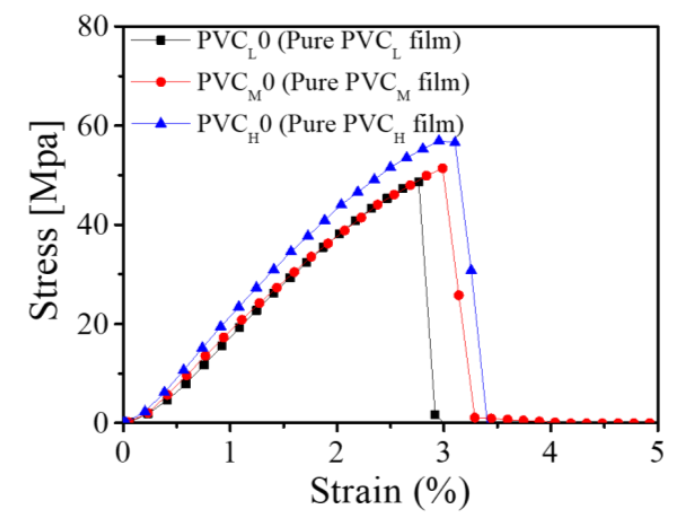

Figure 4. Mechanical property of the pure PVC films.

Figure 5 shows the strain-stress relationships of the PVC gels with different molecular weights and different mixing weight ratios of plasticizer. From Figure 5, we found that the increase of plasticizer in a PVC gel makes the PVC gel soften, and higher molecular weight leads to increased stiffness of the PVC gel. That is, these are two major factors (the weight ratio of PVC to DBA plasticizer and the molecular weight of PVC resin) for adjusting the stiffness of the PVC gel.

The dielectric property is also an important factor in the proposed bending actuator because the proposed actuator has electrically induced actuation behavior. The dielectric constant of a PVC gel was investigated by changing the molecular weight of the PVC resin and the amount of the plasticizer. An SI-1260 impedance/gain-phase analyzer connected with a 1296 dielectric interface (Solartron Analytical Co., Farnborough, UK) was used for the dielectric constant. The input frequency is swept from $1 \mathrm{~Hz}$ to $10^{6} \mathrm{~Hz}$ with 10 points/decade under $2 \mathrm{~V}$ input voltage.

Figure 6 shows the results of dielectric constants of the prepared PVC gels as a function of input frequency. The dielectric constants are increased in the low-frequency range (1-20 Hz). It can be considered that, in a nonionic PVC gel physically crosslinked with plasticizer, DBA molecules are charged and polarized under the electric field, and then the polarized DBA easily facilitates the free dipole reorientation of the PVC chain in the PVC gel network [28]. This dipole reorientation of a PVC gel makes its dielectric constant high. In the high-frequency range $\left(20 \mathrm{~Hz}-10^{6} \mathrm{~Hz}\right)$, the dielectric constants of the PVC gels were almost saturated because the dipoles stop rotation.

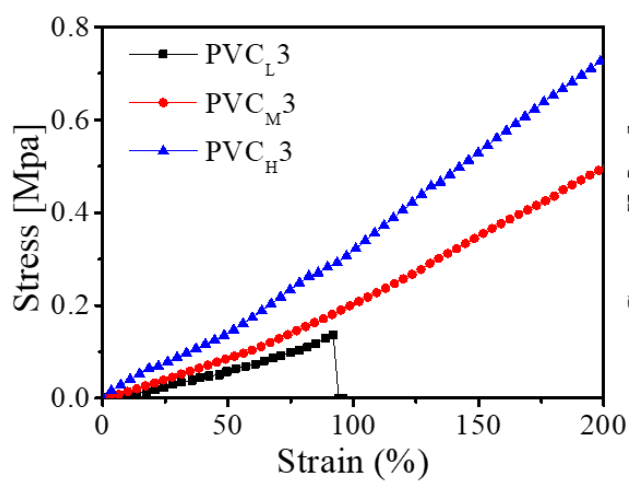

(a)

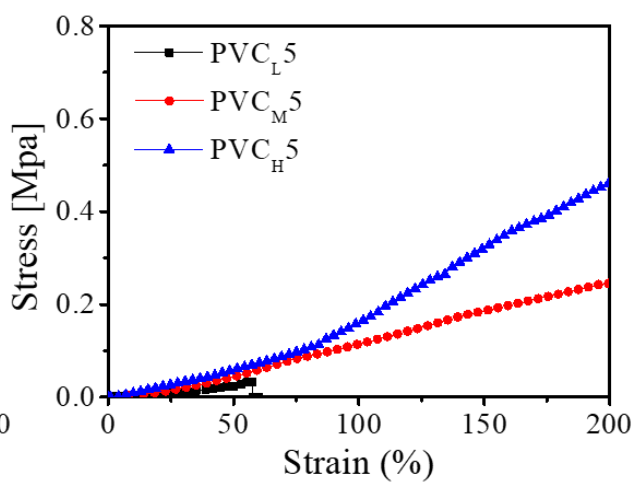

(b)

Figure 5. Cont. 


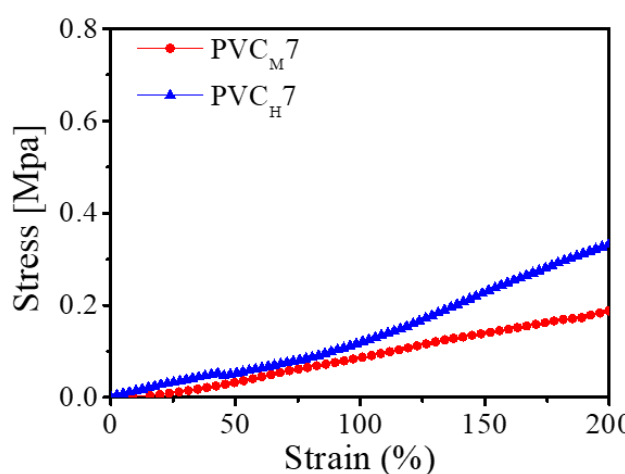

(c)

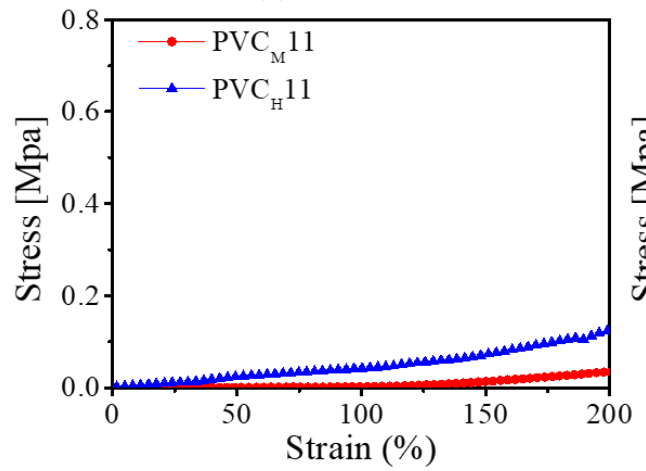

(e)

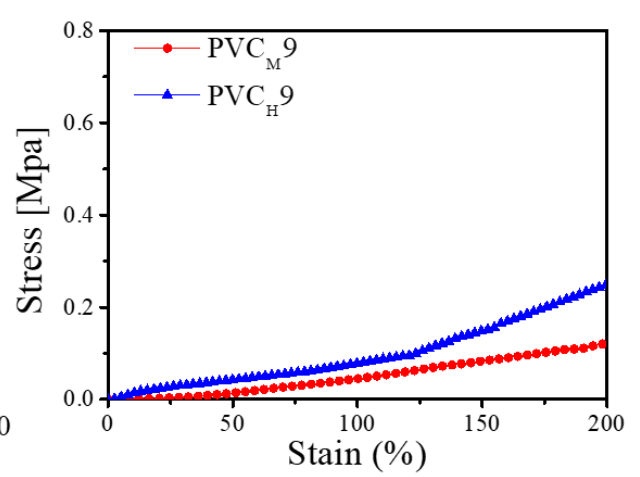

(d)

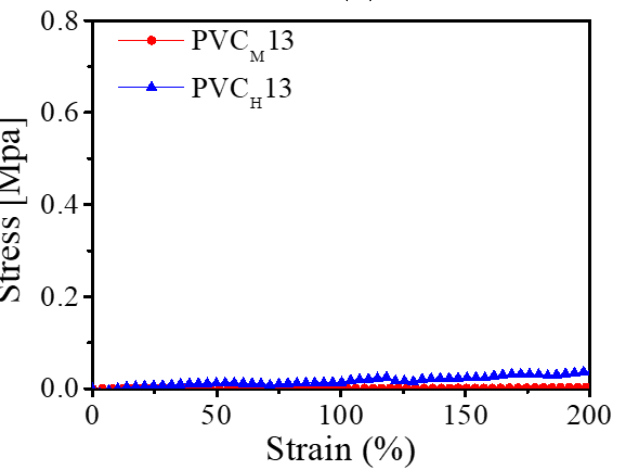

(f)

Figure 5. Experimental results for the mechanical properties of the PVC gels: different molecular weights of PVC with the weight ratio of PVC to DBA plasticizer of (a) 1:3, (b) 1:5, (c) 1:7, (d) 1:9, (e) 1:11, and (f) $1: 13$.

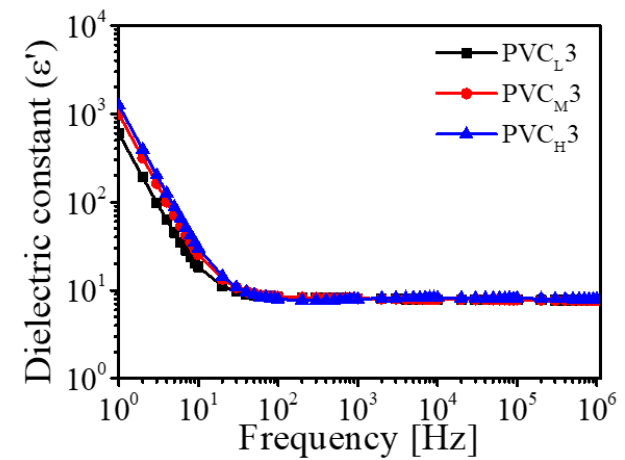

(a)

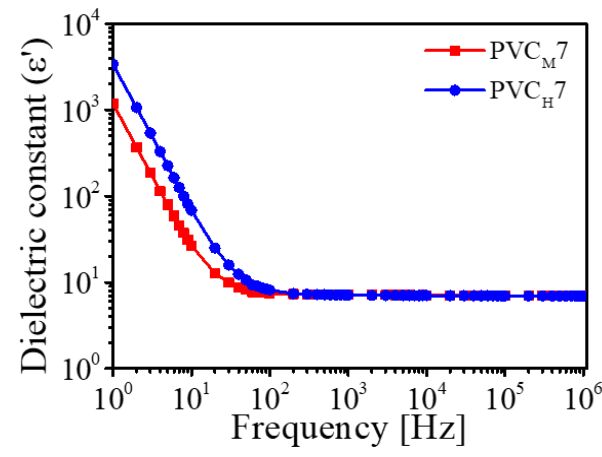

(c)

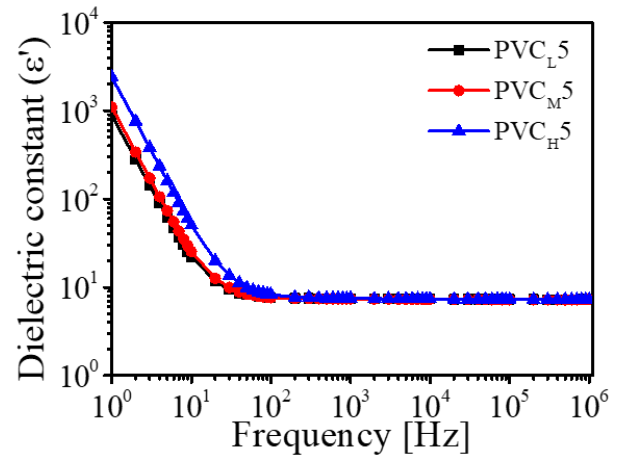

(b)

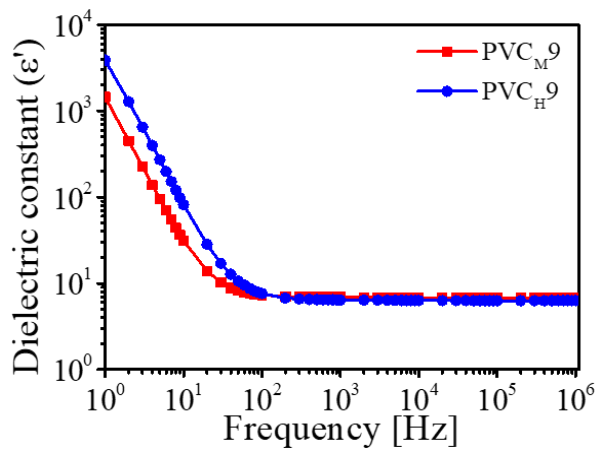

(d)

Figure 6. Cont. 


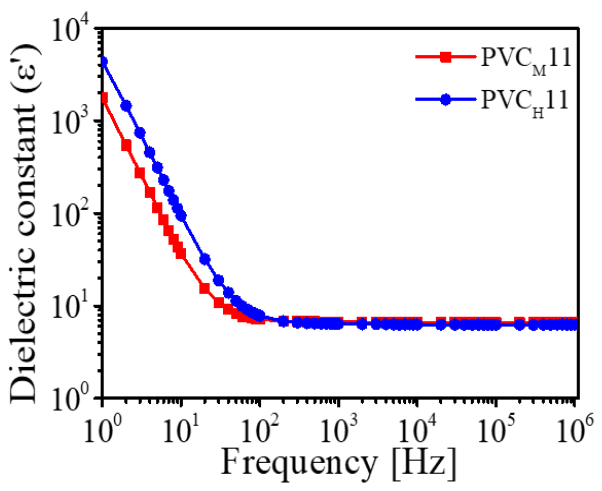

(e)

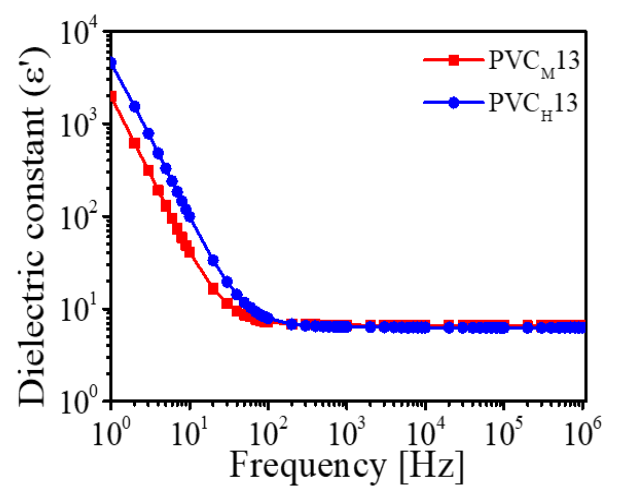

(f)

Figure 6. Experimental results for the dielectric constant of the PVC gels: different molecular weights of PVC with the weight ratio of PVC to DBA plasticizer of (a) 1:3, (b) 1:5, (c) 1:7, (d) 1:9, (e) 1:11, and (f) $1: 13$.

We plotted the dielectric constants of the prepared PVC gels at $1 \mathrm{~Hz}$ (Figure 7). As shown in Figure 7, as the amount of plasticizer increases, the number of dipoles increases, and as a result, the dielectric constant also increases. Furthermore, the dielectric constant is proportional to the molecular weight of the PVC resin (Figure 6). It means that the use of PVC resin with high molecular weight makes entanglement, physical crosslinking and crystallization regions in a PVC gel increase.

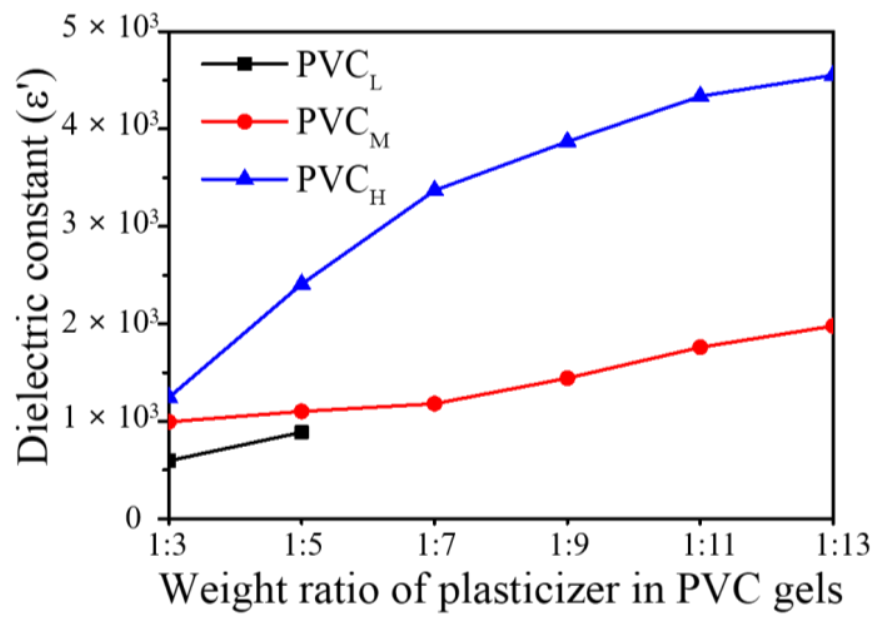

Figure 7. Dielectric constants of the PVC gels at $1 \mathrm{~Hz}$.

The leakage current is another important factor in electrically induced actuation of the proposed bending actuator. The leakage current of the prepared PVC gels was measured by a potentiostat/galvanostat (Bio-logic Science Instruments, SP300) in applied electric fields of $500 \mathrm{~V} / \mathrm{mm}$ at room temperature. Figure 8 shows the results of the prepared samples' leakage currents. It seems that the leakage current in the PVC gel is proportional to the contents of the plasticizer and is inversely proportional to the molecular weight of the PVC. However, there are little differences in leakage currents from the prepared PVC gel samples.

As we mentioned before, we prepared three PVC gel groups $\left(\mathrm{PVC}_{\mathrm{L}}\right.$-based gel, $\mathrm{PVC}_{\mathrm{M}}$-based gel and $\mathrm{PVC}_{\mathrm{H}}$-based gel). In each group, we need to select the best mixing ratio of PVC and a plasticizer using two important properties (dielectric and mechanical properties). The increase of a plasticizer makes a PVC gel soft and it makes its dielectric constant high. Although the increase of the dielectric constant can improve the performance of the PVC gel, the increase of the compliance can disturb the precise movement of the PVC gel-based bending actuator. Thus, we can say that there 
is a trade-off relationship between the dielectric constant of a PVC gel and its stiffness. Considering the dielectric/mechanical properties of the proposed $\mathrm{PVC}$ gel, we selected $\mathrm{PVC}_{\mathrm{L}} 5, \mathrm{PVC}_{\mathrm{M}} 9$ and $\mathrm{PVC}_{\mathrm{H}} 11$ gels. We inserted the following work in the reference section.

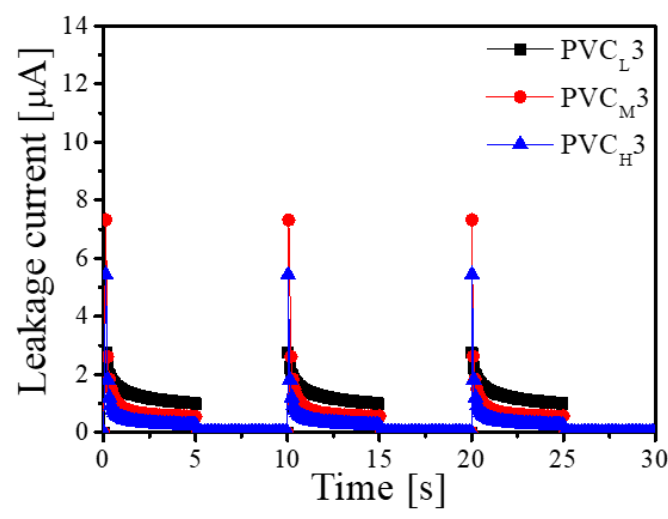

(a)

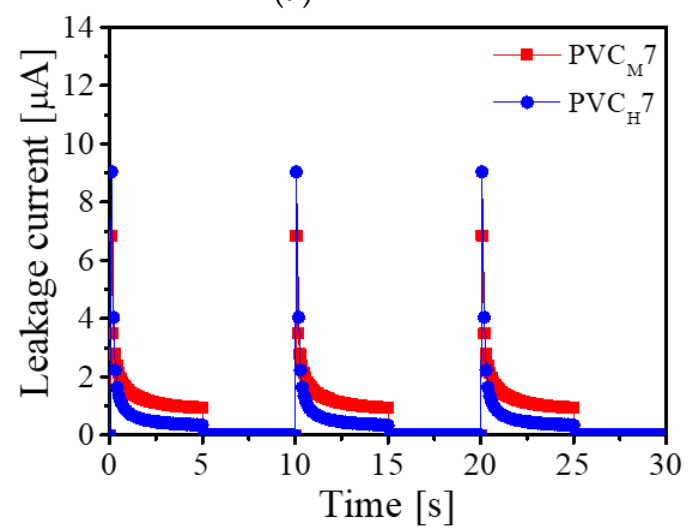

(c)

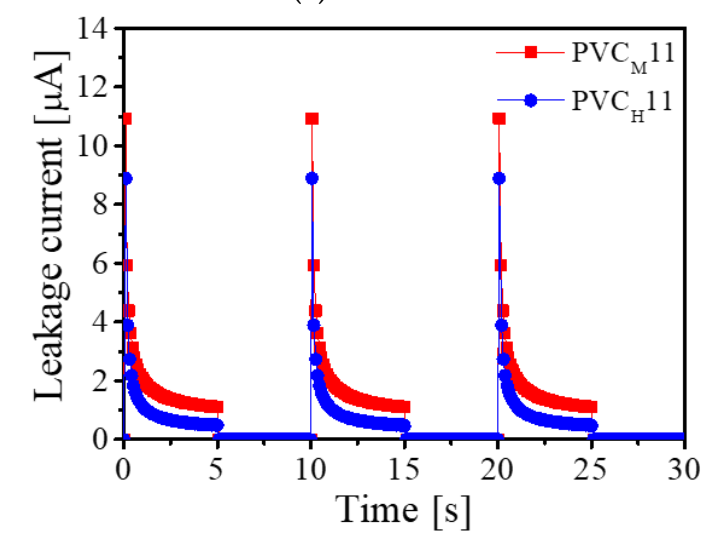

(e)

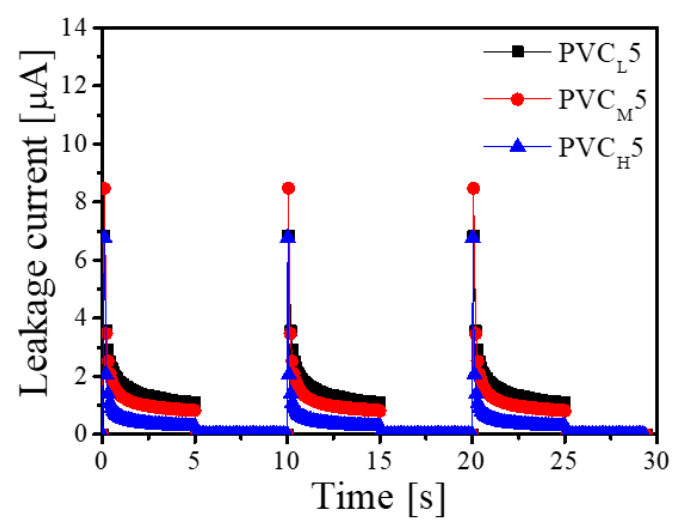

(b)

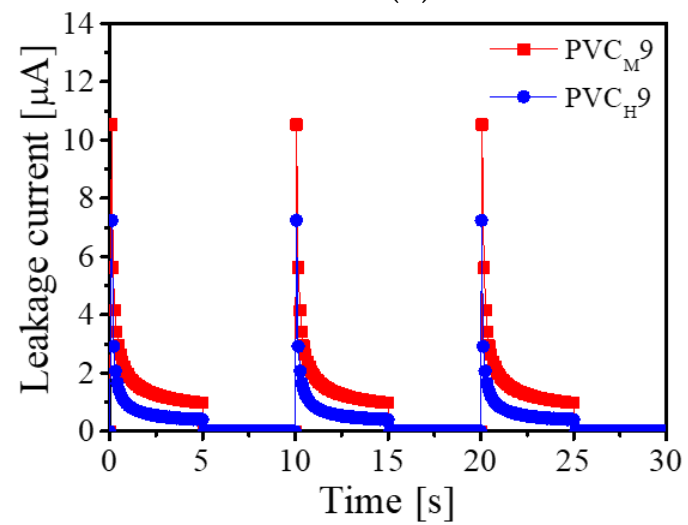

(d)

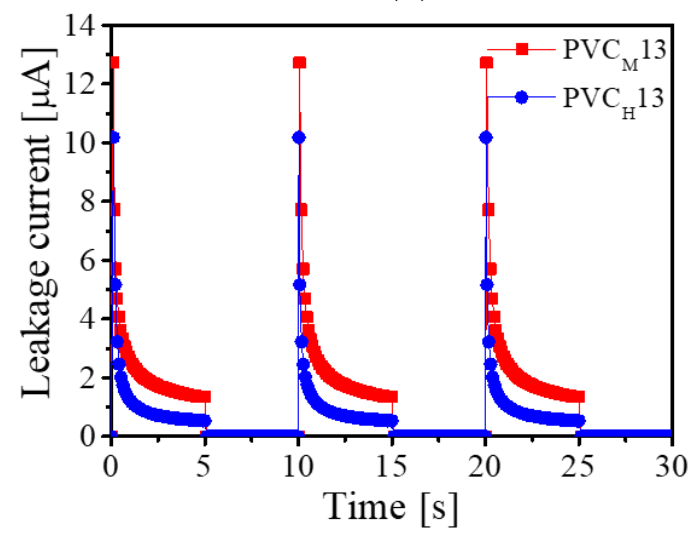

(f)

Figure 8. Experimental results for the leakage current of the PVC gels: different molecular weights of PVC with the weight ratio of PVC to DBA plasticizer of (a) 1:3, (b) 1:5, (c) 1:7, (d) 1:9, (e) 1:11, and (f) $1: 13$.

We conducted an experiment to investigate the dynamic mechanical properties of those three PVC gels $\left(\mathrm{PVC}_{\mathrm{L}} 5, \mathrm{PVC}_{\mathrm{M}} 9\right.$ and $\left.\mathrm{PVC}_{\mathrm{H}} 11\right)$ using a TA Instruments RSA-G2 dynamic mechanical analyzer. Specimens of the three PVC gels were prepared with dimensions of $10 \mathrm{~mm}(\mathrm{~W}) \times 50 \mathrm{~mm}(\mathrm{H}) \times 0.2 \mathrm{~mm}(\mathrm{~T})$. In this experiment, we obtained the dynamic mechanical properties of the PVC gels in the time domain and frequency domain. In the case of the time domain, the PVC gels were strained 10 times $(2 \%$ at 
$1 \mathrm{~Hz}$, sinusoidal), and then the PVC gels were strained with $2 \%$ at $1-50 \mathrm{~Hz}$ (sinusoidal) in the frequency domain. Figure 9a shows the result of the dynamic mechanical analysis in the time domain. The points are the average of the modulus, and the error bars show the standard deviation. The average storage moduli of the $\mathrm{PVC}_{\mathrm{L}} 5, \mathrm{PVC}_{\mathrm{M}} 9$ and $\mathrm{PVC}_{\mathrm{H}} 11$ gels were $13.866,13.923$ and $14.366 \mathrm{kPa}$, respectively. Although the three PVC gels had different plasticizer contents, there was no significant discrepancy in the storage modulus. Figure $9 \mathrm{~b}$ shows the result of the dynamic mechanical analysis (DMA) in the frequency domain. As with the time domain result, there was no significant discrepancy among the three PVC gel samples in the low-frequency range (1-10 Hz), but the moduli of the PVC gels dramatically increased above $10 \mathrm{~Hz}$ and their rates of increase were distinct. In particular, the modulus of the $\mathrm{PVC}_{\mathrm{H}} 11$ gel, which had the longest PVC chains among the three samples, showed a remarkable increase. The maximum modulus of the $\mathrm{PVC}_{\mathrm{H}} 11$ gel reached $299 \mathrm{kPa}$, while the moduli of $\mathrm{PVC}_{\mathrm{L}} 5$ and $\mathrm{PVC}_{\mathrm{M}} 9$ were 66 and $145 \mathrm{kPa}$, respectively. It seems that the modulus of the PVC gel is proportional to the PVC chain length. We found that the valid frequency range of all three PVC gel samples was about $20 \mathrm{~Hz}$.

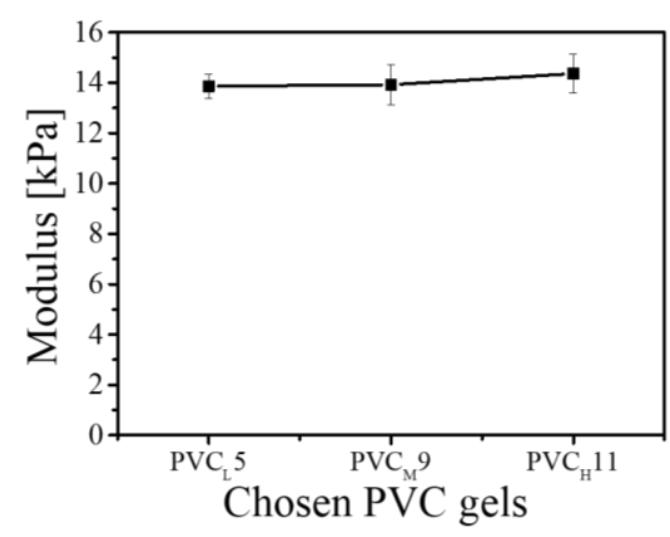

(a)

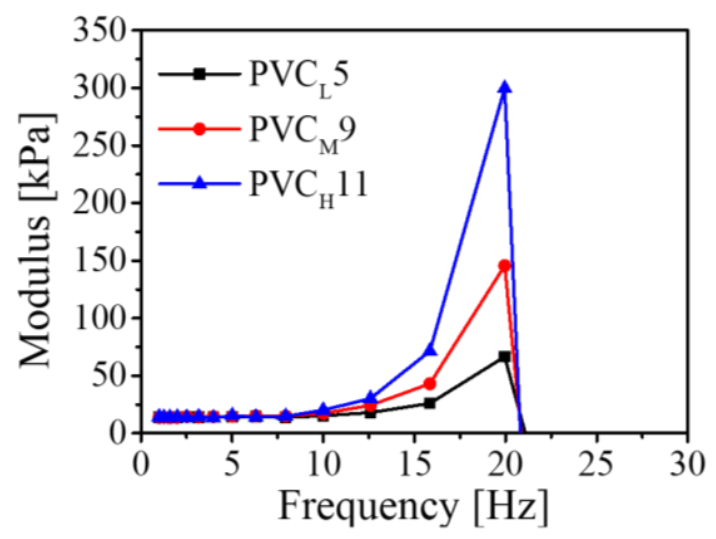

(b)

Figure 9. Dynamic mechanical analysis of PVCs with different molecular weight: (a) Dynamic mechanical analysis (DMA) results in the time domain; and (b) DMA results in the frequency domain.

We fabricated three bending actuators based on the $\mathrm{PVC}_{\mathrm{L}} 5, \mathrm{PVC}_{\mathrm{M}} 9$ and $\mathrm{PVC}_{\mathrm{H}} 11$ gels, and then quantitatively evaluated their actuation performance in terms of response times and deformation angles. To measure these, we designed an experimental environment using a graph paper and a digital camera (1 V3, Nikon, Tokyo, Japan), as shown in Figure 10. To measure the bending angle of the actuator, we installed a wall behind the bending actuator and attached the graph paper to the wall. When we applied a voltage to a PVC gel-based bending actuator, the bending deformation occurred rapidly. At that time, we recorded the bending angle $(\theta)$ using the camera (120 fps) and saved it to memory. After that, the time it took for the bending angle of the proposed actuator to increase by $10^{\circ}$ was calculated through image processing.

Figure 11 shows the measured bending angles of the three transparent actuators over time. The maximum bending angle of the $\mathrm{PVC}_{\mathrm{L}} 5$ gel-based actuator was only about $50^{\circ}$, and its elapsed time was $11 \mathrm{~s}$. On the other hand, the maximum bending angle of the $\mathrm{PVC}_{\mathrm{M}}$ 9- and $\mathrm{PVC}_{\mathrm{H}} 11$-based bending actuators was $180^{\circ}$. However, the elapsed time of the $\mathrm{PVC}_{\mathrm{H}} 11$ gel-based bending actuator (3.154 s) was much faster than that of the $\mathrm{PVC}_{\mathrm{M}} 9$ gel-based bending actuator (194.79 s).

The transparencies of the $\mathrm{PVC}_{\mathrm{M}} 9$ and $\mathrm{PVC}_{\mathrm{H}} 11$ gels were measured using UV-vis spectroscopy. As a result, the $\mathrm{PVC}_{\mathrm{H}} 11$ gel was found to have transparency $>92 \%$ at $550 \mathrm{~nm}$ (Figure 12). From this result, the $\mathrm{PVC}_{\mathrm{H}} 11$ gel-based bending actuator, which had the largest bending angle and the quickest response time, was selected as the most transparent and highly deformable bending actuator. 

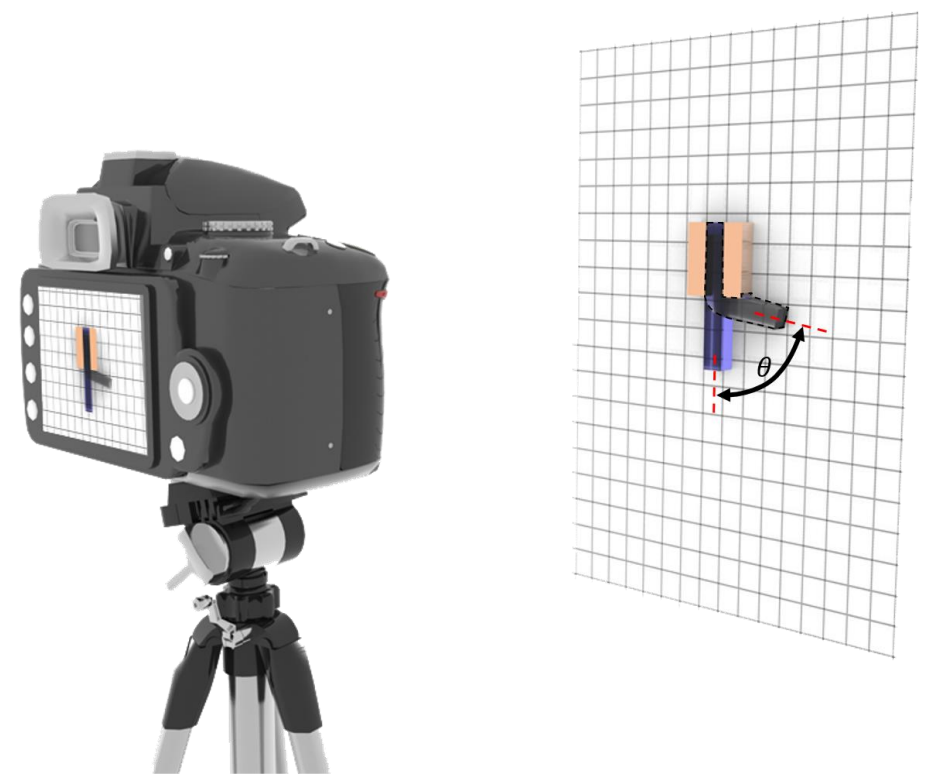

Figure 10. Experimental setup for measuring the actuation performance of the proposed transparent and highly deformable PVC gel-based actuator.

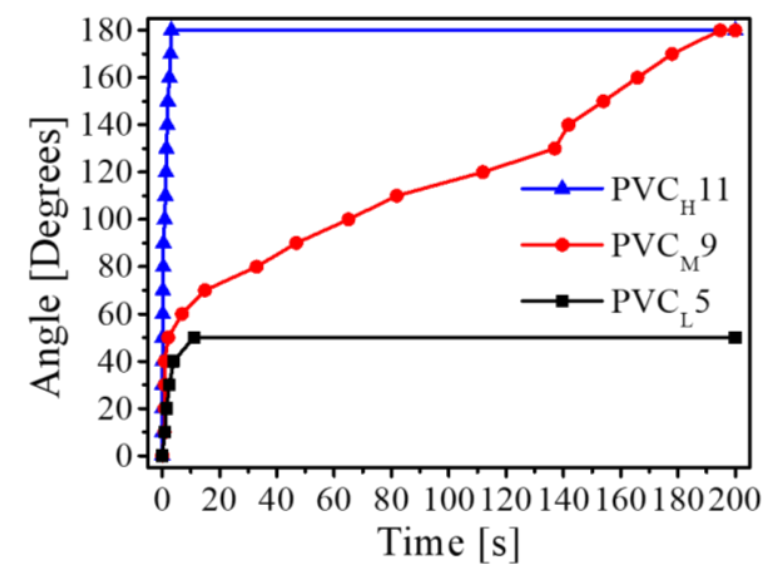

Figure 11. Bending angles of three PVC gels: $\mathrm{PVC}_{\mathrm{L}} 5, \mathrm{PVC}_{\mathrm{M}} 9$ and $\mathrm{PVC}_{\mathrm{H}} 11$.

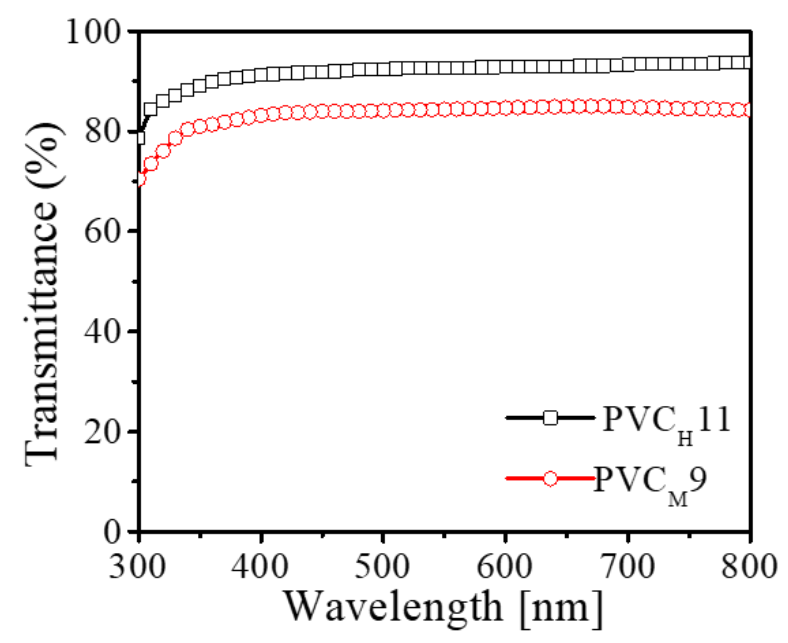

Figure 12. Transmittance of $\mathrm{PVC}_{\mathrm{H}} 11$ and $\mathrm{PVC}_{\mathrm{M}} 9$ gels. 
The thermal stabilities of a pure $\mathrm{PVC}_{\mathrm{H}}$ film and a $\mathrm{PVC}_{\mathrm{H}} 11$ gel were studied by thermogravimetric analysis (TGA) (Figure 13). The TGA thermogram of a pure $\mathrm{PVC}_{\mathrm{H}}$ film showed two degradation steps with onset decomposition at $220^{\circ} \mathrm{C}$. The initial weight-loss step starting at around $220-370{ }^{\circ} \mathrm{C}$ was attributed to the dehydrochlorination in the PVC chains, leading to the formation of long sequences of polyenes, after which the sample had lost $65 \%$ of its weight. The second degradation step is in the range of $370-475{ }^{\circ} \mathrm{C}$, and can be accounted for by the main PVC chains with conjugated double bonds resulting from dehydrochlorination. However, the plasticized $\mathrm{PVC}_{\mathrm{H}} 11$ had slightly reduced thermal stability, and practically, a major steep weight-loss range of $110-320{ }^{\circ} \mathrm{C}$ was noticed compared with that of the pure PVC film. This is because the free volume induced by the presence of DBA plasticizer allows a better diffusion of the hydrochloric acid $(\mathrm{HCl})$ gas produced during dehydrochlorination of PVC $[29,30]$. We inserted the two related works in the reference section.

The maximum bending angle of the $\mathrm{PVC}_{\mathrm{H}} 11$ gel-based actuator was acquired as a function of input voltage. The proposed $\mathrm{PVC}_{\mathrm{H}} 11$ gel-based actuator is hard to bend in lower-voltage input (below $300 \mathrm{~V}$ ) and it starts to actuate as we increase the input voltage. When the input voltage meets $900 \mathrm{~V}$, the bending angle of the actuator becomes $180^{\circ}$ (Figure 14a). Furthermore, we investigated whether the proposed actuator has hysteresis behavior (Figure 14b). In this experiment, we applied $1 \mathrm{kV}$ to the $\mathrm{PVC}_{\mathrm{H}} 11$ gel-based actuator, and we removed the input voltage as soon as the $\mathrm{PVC}_{\mathrm{H}} 11$ gel-based bending actuator reached $180^{\circ}$. The actuator quickly reached $90^{\circ}$ within $0.415 \mathrm{~s}$, and the bending angle of the actuator gradually increased until the angle reached $180^{\circ}$ (3.154 s). After removing the voltage input, the proposed actuator returned to its initial shape.

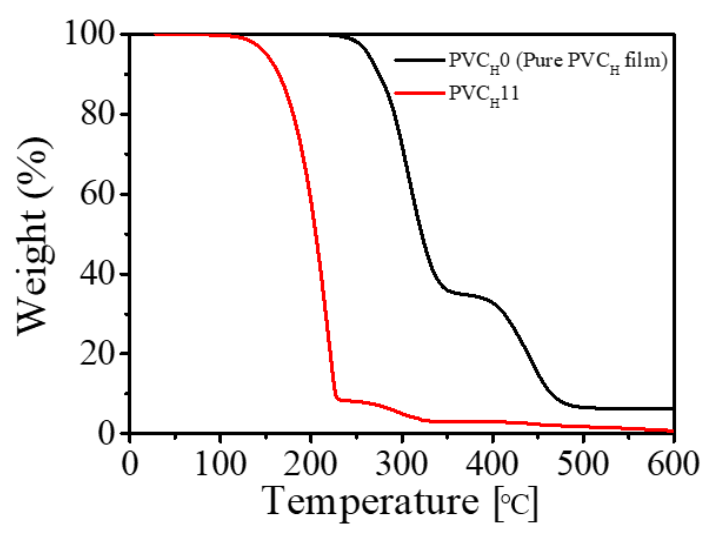

Figure 13. TGA result of the pure PVC film and $\mathrm{PVC}_{\mathrm{H}} 11$.

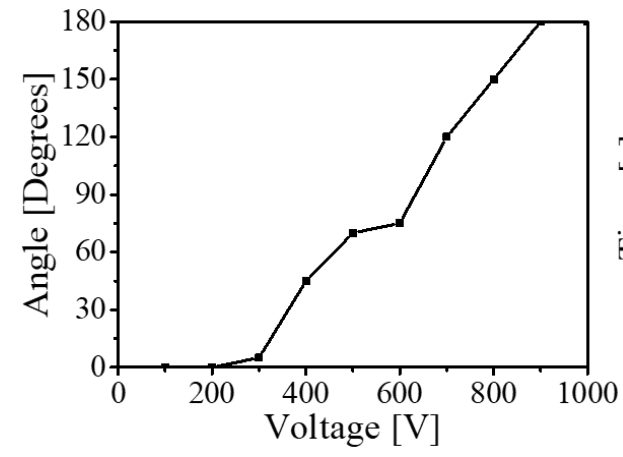

(a)

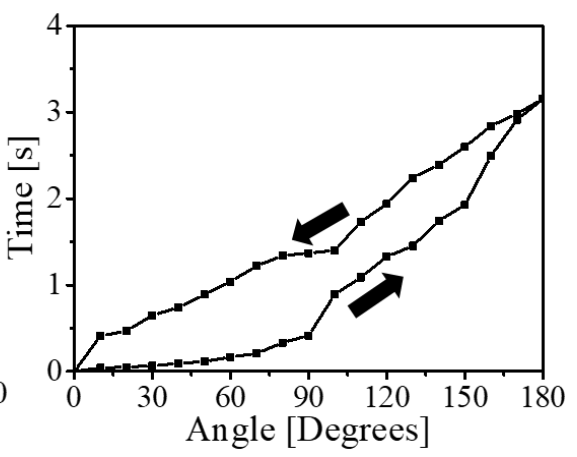

(b)

Figure 14. Bending behavior of the $\mathrm{PVC}_{\mathrm{H}} 11$ gel-based actuator. (a) Maximum bending angle of the proposed actuator according to the voltage input; (b) hysteresis of the actuator.

To verify the cycling performance of the proposed actuator, square $\mathrm{AC}$ input voltage (0 to $1 \mathrm{kV}_{\mathrm{pp}}$ ) was applied to the $\mathrm{PVC}_{\mathrm{H}} 11$ gel-based bending actuator. The input voltage of $1 \mathrm{kV}$ was 
applied to the proposed bending actuator over $5 \mathrm{~s}$ and then $0 \mathrm{~V}$ was provided to the actuator for $5 \mathrm{~s}$. This procedure was conducted 25,000 times (about three days). Figure 15 shows the results of the proposed actuator's cycling performance. There is no significant difference in the maximum bending angle of the $\mathrm{PVC}_{\mathrm{H}} 11$ gel-based proposed actuator. From the result, the actuation cycles of the actuator were reproducible, indicating that the proposed actuator showed long-term durability. Taking all experimental results together, we found that the $\mathrm{PVC}_{\mathrm{H}} 11$ gel-based actuator has the highest transparency and the best performance.

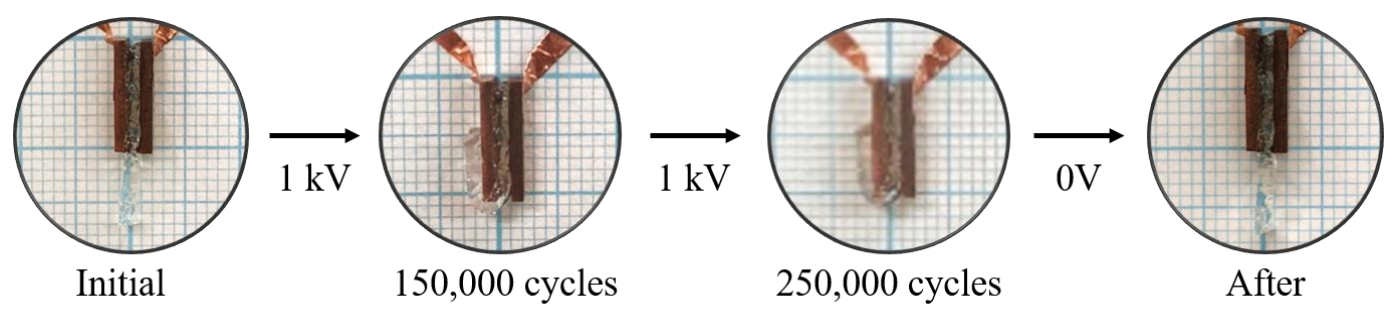

Figure 15. The result of the cycling performance for the $\mathrm{PVC}_{\mathrm{H}} 11$ gel-based bending actuator.

\section{Conclusions}

A small, transparent, electroactive and highly deformable PVC gel-based bending actuator was fabricated and evaluated. Three PVC samples with different molecular weights were prepared, and then the three samples were mixed with plasticizer at various ratios to produce 17 PVC gels. After this, the mechanical properties of the prepared PVC gels were investigated according to their molecular weight and plasticizer content. The stiffness of the PVC gel was increased by increasing the molecular weight of the PVC gel, whereas the stiffness was decreased by increasing the amount of plasticizer. Judging from the results, we selected the $\mathrm{PVC}_{\mathrm{L}} 5, \mathrm{PVC}_{\mathrm{M}} 9$ and $\mathrm{PVC}_{\mathrm{H}} 11$ gels and from them, fabricated transparent, highly deformable bending actuators. The dynamic mechanical property of the selected three PVC gels was investigated using a dynamic mechanical analyzer in time and frequency domains. We found that there was little significant discrepancy in the three PVC gels and that their valid frequency range was about $20 \mathrm{~Hz}$. Furthermore, we investigated their response time and their maximum bending angle quantitatively. As a result, the $\mathrm{PVC}_{\mathrm{H}} 11$ gel-based bending actuator showed the maximum bending angle and fastest response time $\left(180^{\circ}\right.$ with elapsed time of $\left.3.15 \mathrm{~s}\right)$. In addition, the $\mathrm{PVC}_{\mathrm{H}} 11$ gel had high transparency $(92 \%)$.

Author Contributions: E.-J.S. designed the research problems; E.-J.S. and W.-H.P. conducted the experiments and analyzed the results; S.-Y.K. supervised the research. All authors discussed the results and wrote the paper.

Funding: This work was supported by the Technology Innovation Program (10077367, Development of a film-type transparent/stretchable 3-D touch sensor/haptic actuator combined module and advanced UI/UX) funded by the Ministry of Trade, Industry, \& Energy (MOTIE, Korea). This work was supported by Priority Research Centers Program through the National Research Foundation of Korea (NRF) funded by the Ministry of Education, Science and Technology (NRF-2018R1A6A1A03025526).

Acknowledgments: Thank the Cooperative Equipment Center at Koreatech for assistance with UV-vis and TGA analyses.

Conflicts of Interest: The authors declare no conflict of interest.

\section{References}

1. Steltz, E.; Mozeika, A.; Rembisz, J.; Corson, N.; Jaeger, H.M. Jamming as an enabling technology for soft robotics. In SPIE Electroactive Polymer Actuators and Devices (EAPAD); International Society for Optics and Photonics: San Diego, CA, USA, 2010.

2. Chen, L.; Liu, C.; Liu, K.; Meng, C.; Hu, C.; Wang, J.; Fan, S. High-performance, low-voltage, and easy-operable bending actuator based on aligned carbon nanotube/polymer composites. ACS Nano 2011, 5, 1588-1593. [CrossRef] [PubMed] 
3. Yoon, W.J.; Reinhall, P.G.; Seibel, E.J. Analysis of electro-active polymer bending: A component in a low cost ultrathin scanning endoscope. Sens. Actuators A: Phys. 2007, 133, 506-517. [CrossRef]

4. Wang, W.; Lee, J.-Y.; Rodrigue, H.; Song, S.-H.; Chu, W.-S.; Ahn, S.-H. Locomotion of inchworm-inspired robot made of smart soft composite (SSC). Bioinspir. Biomim. 2014, 9, 046006. [CrossRef] [PubMed]

5. Chen, L.; Weng, M.; Zhou, Z.; Zhou, Y.; Zhang, L.; Li, J.; Huang, Z.; Zhang, W.; Liu, C.; Fan, S. Large-Deformation Curling Actuators Based on Carbon Nanotube Composite: Advanced-Structure Design and Biomimetic Application. ACS Nano 2015, 9, 12189-12196. [CrossRef] [PubMed]

6. Shahinpoor, M. Ionic polymer-Conductor composites as biomimetic sensors, robotic actuators and artificial muscles-A review. Elecrochim. Acta 2003, 45, 2343-2353. [CrossRef]

7. Must, I.; Kaasik, F.; Põldsalu, I.; Mihkels, L.; Johanson, U.; Punning, A.; Aabloo, A. Ionic and Capacitive Artificial Muscle for Biomimetic Soft Robotics. Adv. Eng. Mater. 2014, 17, 84-94. [CrossRef]

8. Khan, A.; Ravi, K.J.; Abdullah, M.A. Thorium (IV) phosphate-polyaniline composite-based hydrophilic membranes for bending actuator application. Polym. Eng. Sci. 2017, 57, 258-267. [CrossRef]

9. Wang, F.; Kim, S.-S.; Kee, C.-D.; Shen, Y.-D.; Oh, I.-K. Novel electroactive PVA-TOCN actuator that is extremely sensitive to low electrical inputs. Smart Mater. Struct. 2014, 23, 074006. [CrossRef]

10. Wang, X.; Oh, I.-K.; Lee, S. Electroactive artificial muscle based on crosslinked PVA/SPTES. Sens. Actuators $B$ Chem. 2010, 150, 57-64. [CrossRef]

11. Shi, J.; Guo, Z.-X.; Zhan, B.; Luo, H.; Li, Y.; Zhu, D. Actuator based on MWNT/PVA hydrogels. J. Phys. Chem. B 2005, 109, 14789-14791. [CrossRef] [PubMed]

12. Zhao, G.; Wang, J.; Xu, Y.; Muhammad, F. Development of biocompatible polymer actuator consisting of biopolymer chitosan, carbon nanotubes, and an ionic liquid. Polym. Compos. 2017, 38, 1609-1615. [CrossRef]

13. Gao, L.; Guo, G.; Liu, M.; Tang, Z.; Xie, L.; Huo, Y. Multi-responsive, bidirectional, and large deformation bending actuators based on borax cross-linked polyvinyl alcohol derivative hydrogel. RSC Adv. 2017, 7, 40005-40014. [CrossRef]

14. Sun, J.-K.; Lin, H.-J.; Zhang, W.-Y.; Gao, M.-R.; Antonietti, M.; Yuan, J. A tale of two membranes: From poly(ionic liquid) to metal-organic framework hybrid nanoporous membranes via pseudomorphic replacement. Mater. Horiz. 2017, 4, 681-687. [CrossRef]

15. Shintake, J.; Rosset, S.; Schubert, B.; Floreano, D.; Shea, H. Versatile soft grippers with intrinsic electroadhesion based on multifunctional polymer actuators. Adv. Mater. 2016, 28, 231-238. [CrossRef] [PubMed]

16. Guggi, K.; Paajanen, M.; Bauer, S. Self-organized minimum-energy structures for dielectric elastomer actuators. Appl. Phys. A 2006, 85, 141-143. [CrossRef]

17. Chilibon, I.; Dias, C.; Inacio, P.; Marat-Mendes, J. PZT and PVDF bimorph actuators. J. Optoelectron. Adv. Mater. 2007, 9, 1939-1943.

18. Mejri, R.; Dias, J.C.; Besbes Hentati, S.; Botelho, G.; Esperanca, J.M.S.S.; Costa, C.M.; Lanceros-Mendez, S. Imidazolium-based ionic liquid type dependence of the bending response of polymer actuators. Eur. Polym. J. 2016, 85, 445-451. [CrossRef]

19. Gaihre, B.; Alici, G.; Spinks, G.M.; Cairney, J.M. Synthesis and performance evaluation of thin film PPy-PVDF multilayer electroactive polymer actuators. Sens. Actuator A Phys. 2011, 165, 321-328. [CrossRef]

20. Chen, T.; Liu, B. Graphene quantum dot-poly(vinylidene fluoride) composite for the preparation of asymmetric bilayer bending transducer. J. Mater. Sci.-Mater. 2018, 29, 5206-5212. [CrossRef]

21. Asaka, K.; Hidenori, O. Soft Actuators: Materials, Modeling, Applications, and Future Perspectives; Springer: Berlin, Germany, 2014.

22. Uddin, Z.; Watanabe, M.; Shirai, H.; Hirai, T. Effects of Plasticizers on Novel Electromechanical Actuations with Different Poly(vinyl chloride) Gels. J. Polym. Sci. Part B: Polym. Phys. 2003, 41, 2119-2127. [CrossRef]

23. Bae, J.W.; Yeo, M.; Shin, E.-J.; Park, W.-H.; Lee, J.E.; Nam, B.-U.; Kim, S.-Y. Eco-friendly plasticized poly(vinyl chloride)-acetyl tributyl citrate gels for varifocal lens. RSC Adv. 2015, 5, 94919-94925. [CrossRef]

24. Kim, S.-Y.; Yeo, M.; Shin, E.-J.; Park, W.-H.; Jang, J.-S.; Nam, B.-U.; Bae, J.W. Fabrication and evaluation of variable focus and large deformation plano-convex microlens based on non-ionic poly(vinyl chloride)/dibutyl adipate gels. Smart Mater. Struct. 2015, 24, 115006. [CrossRef]

25. Ballard, D.G.H.; Burgess, A.N.; Dekoninck, J.M.; Roberts, E.A. The 'crystallinity' of PVC. Polymer 1987, 28, 3-9. [CrossRef]

26. Beltrán, M.; García, J.C.; Marcilla, A. Infrared spectral changes in PVC and plasticized PVC during gelation and fusion. Eur. Polym. J. 1997, 33, 453-462. [CrossRef] 
27. Shin, E.-J.; Bae, J.W.; Jeong, J.; Choi, D.-S.; Lee, J.E.; Nam, B.U.; Lin, L.; Kim, S.-Y. High-Performance PVC Gel for Adaptive Micro-Lenses with Variable Focal Length. Sci. Rep. 2017, 7, 2068. [CrossRef]

28. Ali, M.; Ueki, T.; Tsurumi, D.; Hirai, T. Influence of plasticizer content on the transition of electromechanical behavior of PVC gel actuator. Langmuir 2011, 27, 7902-7908. [CrossRef] [PubMed]

29. Aouachria, K.; Massardier-Nageote, V.; Belhaneche-Bensemra, N. Thermal stability and Kinetic Study of rigid and plasticized Poly(vinyl chloride)/Poly(methylmethacrylate) blends. J. Vinyl Addit. Technol. 2015, 21, 102-110. [CrossRef]

30. Van Der Ven, S.; De Wit, W.F. Thermal degradation of poly(vinyl chloride): The accelerating effect of hydrogen chloride. Die Angew. Makromol. Chem.: Appl. Macromol. Chem. Phys. 1969, 8, 143-152. [CrossRef]

(C) 2018 by the authors. Licensee MDPI, Basel, Switzerland. This article is an open access article distributed under the terms and conditions of the Creative Commons Attribution (CC BY) license (http://creativecommons.org/licenses/by/4.0/). 